\title{
Estimulação precoce em crianças prematuras durante visita domiciliar
}

\author{
Early stimulation in premature children during home visit \\ Estimulación temprana en niños prematuros durante la visita domiciliaria
}

Recebido: 20/07/2021 | Revisado: 29/07/2021 | Aceito: 03/08/2021 | Publicado: 08/08/2021

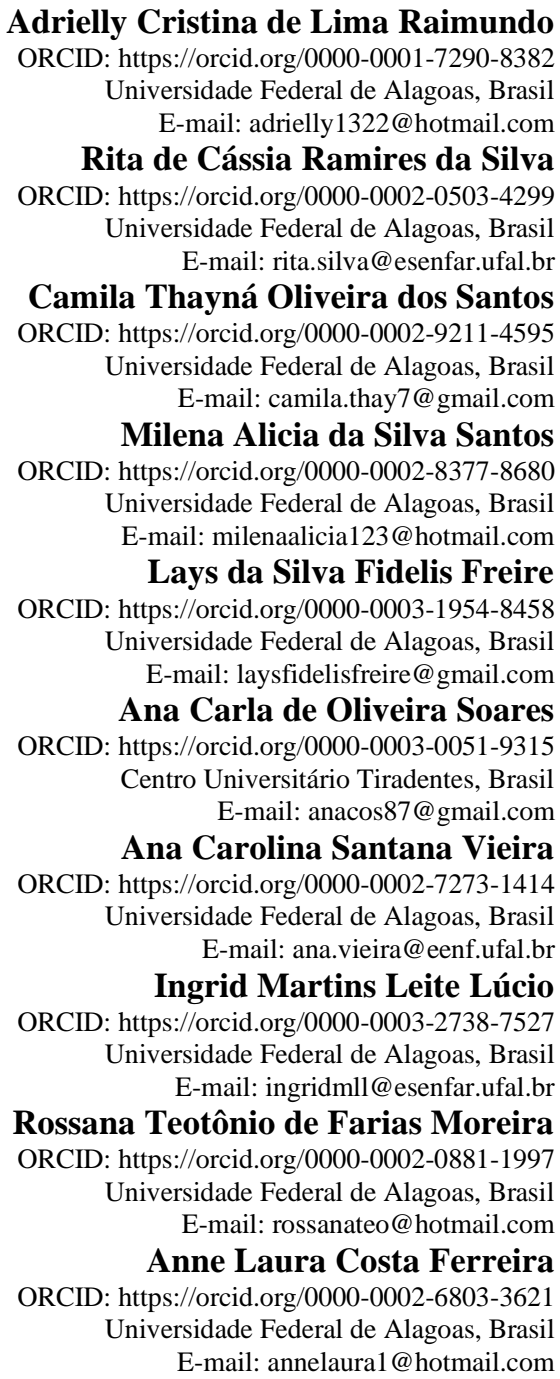

\section{Resumo}

Objetivo: Avaliar os resultados da estimulação precoce global em crianças prematuras durante visita domiciliar. Método: Pesquisa qualitativa, do tipo pesquisa-ação, realizada durante visita domiciliar em parceria com a Estratégia de Saúde da Família (ESF) de um bairro da periferia da cidade de Maceió, Alagoas. Foi realizada a avaliação e o acompanhamento de duas crianças, vinculadas à ESF. Os dados foram coletados a partir de entrevista semiestruturada e realização de exame físico, usando como base os marcos e gráficos disponibilizados pelo Ministério da Saúde e à luz do referencial teórico de Vigotski. Com base nos achados, foi realizado o planejamento de atividades que foram aplicadas em parceira com os genitores, no período de quatro semanas, sendo feita com o pesquisador uma vez por semana durante este período, e com reavaliação das crianças no último encontro. Resultados: Evidenciou-se que fatores como a idade materna e a renda foram fatores que influenciam negativamente o desenvolvimento infantil. Da mesma forma, que o acompanhamento do crescimento e desenvolvimento $(\mathrm{CD})$ de prematuros na atenção básica não ocorre de forma satisfatória, sendo priorizadas as consultas em ambiente hospitalar. A estimulação global precoce contribuiu de forma positiva para as crianças do estudo, mas quando realizada no cotidiano da família. Conclusão: Ressalta-se a importância de profissional enfermeiro não só na vigilância ao $\mathrm{CD}$, mas também como atuante na realização da 
estimulação precoce. Como limitação, o estudo trouxe um número pequeno de crianças avaliadas, e por isso, sugere-se a realização de pesquisas com um número ampliado para uma avaliação mais fidedigna.

Palavras-chave: Intervenção educacional precoce; Crescimento e desenvolvimento; Recém-nascido prematuro; Visita domiciliar.

\begin{abstract}
Objective: To evaluate the results of early global stimulation in preterm children during home visits. Method: Qualitative research, action-research type, carried out during home visits and in partnership with the Family Health Strategy in a neighborhood on the outskirts of the city of Maceió, Alagoas. The evaluation and monitoring of two children linked to the ESF was carried out. Data were collected through semi-structured interviews and physical examination, using as a basis the charts and graphs provided by the Ministry of Health and in the light of Vigotski's theoretical framework. Based on the findings, activities were planned and applied in partnership with the parents, over a period of four weeks, being carried out with the researcher once a week during this period, and with reassessment of the children in the last meeting. Results: It was evidenced that factors such as maternal age and income are factors that negatively influence child development. Likewise, the follow-up to the DC of premature infants in primary care does not occur satisfactorily, with consultations in the hospital environment being prioritized. Early global stimulation contributed positively to the children in the study, but when performed in the family's daily life. Conclusion: The importance of a professional nurse is highlighted, not only in the surveillance of the DC, but also as an agent in carrying out early stimulation. As a limitation, the study brought a small number of children evaluated, and therefore, it is suggested to carry out research with an increased number for a more reliable evaluation.
\end{abstract}

Keywords: Early intervention, Educational; Growth and development; Infant, premature; House calls.

\title{
Resumen
}

Objetivo: Evaluar los resultados de la estimulación global temprana en niños prematuros durante las visitas domiciliarias. Método: Investigación cualitativa, tipo investigación-acción, realizada durante visitas domiciliarias y en alianza con la Estrategia Salud de la Familia en un barrio de las afueras de la ciudad de Maceió, Alagoas. Se llevó a cabo la evaluación y seguimiento de dos niños vinculados al FSE. Los datos fueron recolectados a través de entrevistas semiestructuradas y examen físico, utilizando como base los cuadros y gráficos proporcionados por el Ministerio de Salud y a la luz del marco teórico de Vigotski. A partir de los hallazgos, se planificaron y aplicaron actividades en asociación con los padres, durante un período de cuatro semanas, realizándose con el investigador una vez por semana durante este período, y con reevaluación de los niños en la última reunión. Resultados: Se evidenció que factores como la edad materna y los ingresos son factores que influyen negativamente en el desarrollo infantil. Asimismo, el seguimiento a la CD de prematuros en atención primaria no se da de forma satisfactoria, priorizándolos las consultas en el ámbito hospitalario. La estimulación global temprana contribuyó positivamente a los niños del estudio, pero cuando se realizó en la vida diaria de la familia. Conclusión: Se destaca la importancia de una enfermera profesional, no solo en la vigilancia de la $\mathrm{CD}$, sino también como agente en la realización de estimulación precoz. Como limitación, el estudio trajo una pequeña cantidad de niños evaluados, por lo que se sugiere realizar investigaciones con un número mayor para una evaluación más confiable.

Palabras clave: Intervención educativa precoz; Crecimiento y desarrollo; Recién nacido prematuro; Visites à domicile.

\section{Introdução}

O crescimento e o desenvolvimento infantil resultam da congruência entre fatores biológicos, socioeconômicos e ambientais que podem contribuir de forma positiva ou negativa na aquisição e maturação de habilidades (Neves et al., 2016). Lev Vygotsky afirma ainda que o desenvolvimento está associado ao meio sociocultural e às relações que a criança desenvolve com as pessoas à sua volta, tendo o brinquedo e a brincadeira um importante aspecto nesse processo (Dos Santos Teixeira, 2017).

O crescimento consiste num processo dinâmico e contínuo representado pelo aumento de tamanho corporal; enquanto isso, o desenvolvimento é um conceito amplo e denomina uma transformação complexa, contínua, dinâmica e progressiva que incluem crescimento, maturação, aprendizagem, aspectos psíquicos e sociais, além da fase intrauterina (Brasil, 2012; Matos; Cavalcante; Costa, 2016).

Crianças prematuras, ou seja, aquelas nascidas com idade gestacional inferior a 37 semanas (OMS), apresentam determinado risco em relação ao seu neurodesenvolvimento, que pode interferir nas capacidades funcionais, cognitivas e comportamentais, e provocar agravos ao desenvolvimento nas áreas física, cognitiva, emocional e social da criança (Granemann; Anache, 2017). 
Foi evidenciado ainda, num estudo que avaliou o crescimento e desenvolvimento de crianças que nasceram prematuras com peso ao nascimento $<1500 \mathrm{~g}$ e acompanhadas até os dois anos de idade, que elas apresentaram um desenvolvimento motor atípico (Almeida, 2016). Também verificou-se a presença de alterações no desenvolvimento relacionado à linguagem (Balam, 2018), acuidade motora, provas de equilíbrio e tônus postural.

Nos três primeiros anos de vida, período denominado como primeiríssima infância, as interações que a criança promove com o mundo a sua volta são capazes de remodelar suas conexões cerebrais, seu aprendizado e memória, o que é consequência da plasticidade cerebral, ou seja, da capacidade do Sistema Nervoso Central (SNC) de se adaptar às condições do ambiente, condição que reduz ao longo dos anos, mas que é bastante ativa até os seis anos de idade (Souza; Campos; Júnior, 2013; Teixeira; Lôbo; Duarte, 2016).

Nesse sentido, ressalta-se a importância da promoção e proteção ao desenvolvimento infantil, que pode ser evidenciado ao longo dos anos pela instituição de programas e Políticas com este objetivo, dentre os quais a Política Nacional de Atenção Integral à Saúde da Criança (PNAISC), que traz como um de seus eixos estratégicos a promoção e o acompanhamento do crescimento e do desenvolvimento infantil pela atenção básica à saúde (Brasil, 2015).

Outra legislação importante, principalmente no que se refere ao cuidado aos prematuros, é o Método Canguru, que prevê estratégias que visam à humanização do cuidado, a redução da mortalidade neonatal, o estímulo ao aleitamento materno e ao desenvolvimento neurocomportamental, entre outros. O acompanhamento deve ser iniciado no pré-natal, e seguir pelo primeiro ano de vida, tanto na atenção ambulatorial como na Atenção Primária à Saúde (APS) (Brasil, 2019).

Assim, é no contexto da primeira infância que a estimulação precoce pode ser inserida. Definida como uma intervenção de caráter sistêmico e sequencial, que usa técnicas e recursos que estimulam os domínios que influenciam a maturação e aquisição de habilidades, objetiva ampliar as competências e reduzir efeitos negativos que a criança tenha sofrido, impulsionando o seu desenvolvimento (Moreira; Sodré, 2018; Brasil, 2016; Monteiro, 2018).

A consulta de enfermagem em puericultura pode ser utilizada como meio para a vigilância e avaliação do crescimento e desenvolvimento infantil, oportunizando o rastreamento de eventuais atrasos de forma precoce e viabilizando o encaminhamento para um centro de referência, quando necessário (Gaíva et al., 2017). Como profissional atuante na atenção primária, o enfermeiro faz a vigilância do desenvolvimento infantil junto às famílias, compartilhando saberes, sanando dúvidas e avaliando indicadores (Yakuwa; Neill; Mello, 2018).

Junto ao acompanhamento da criança na puericultura, a visita domiciliar (VD) é um instrumento estratégico da atenção primária, que possibilita uma visão ampliada dos determinantes e condicionantes que podem interferir na saúde do indivíduo, e para o público infantil, possibilita, entre outras coisas, vigilância, investigação de indicadores, segurança e oportunidade de experiências adequadas para o desenvolvimento, como por exemplo, a estimulação precoce (Dos Santos Teixeira, 2017; Mello et al., 2017).

Além disso, crianças prematuras tendem a apresentar maiores necessidades no domicílio, com mais dificuldades dos cuidadores e possíveis erros em relação à alimentação, medicação e demais cuidados básicos. Dessa forma, a presença ativa de profissionais de saúde no domicílio, por meio da visita domiciliar, pode antecipar a identificação de erros e dificuldades dos cuidadores, ajudando-os a empregar práticas eficazes para potencializar a atenção à saúde da criança e promover o seu desenvolvimento sadio (Silva et al., 2020).

Isto posto, considerando que crianças prematuras têm uma alteração de desenvolvimento relacionada ao nascimento antes do tempo e que a estimulação precoce pode ser um fator protetivo, o presente estudo teve por objetivo avaliar as respostas da estimulação precoce no desenvolvimento de crianças com história de prematuridade, mediante o ambiente da visita domiciliar no contexto da Atenção Primária à Saúde. 


\section{Metodologia}

Trata-se de um estudo qualitativo, do tipo pesquisa-ação, no qual se propõem a participação ativa das pessoas envolvidas para o entendimento do fenômeno dentro do ambiente em que ocorre, levando tanto a produção de resultados como a uma ação social (Anunciação et al., 2018; Thiollent, 2018). A distribuição das etapas da pesquisa-ação muda conforme o autor, entretanto, Anunciação e colaboradores (2018) sugerem cinco fases: conhecimento da realidade, planejamento de ações, efetivação das ações planejadas, avaliação dos resultados obtidos e identificação do aprendizado obtido a partir do problema.

A coleta de dados ocorreu no ambiente da visita domiciliar, vinculada à uma Unidade de Saúde da Família localizada num bairro da periferia do município de Maceió, Alagoas. A abordagem foi realizada durante visita domiciliar, com o auxílio dos Agentes Comunitários de Saúde (ACS), onde foi explicada a pesquisa, seu objetivo e suas etapas; como se realizar uma primeira avaliação da criança em relação aos marcos de crescimento e desenvolvimento infantil, bem como a coleta da sua história anterior de internação, segundo um formulário próprio. A partir da assinatura do Termo de Consentimento Livre e Esclarecido - TCLE, a coleta foi iniciada e executados os próximos passos. A coleta ocorreu entre os meses de janeiro a março de 2020. Foram acompanhadas, nesse período, duas crianças nascidas com idade gestacional menor que 37 semanas e que passaram por internação em Unidade de Terapia Intensiva Neonatal.

A presente pesquisa seguiu as seguintes etapas:

a) conhecimento da realidade - foi realizada coleta de dados que reunia as informações relacionadas à gravidez, parto e histórico de internação, além da avaliação dos marcos de crescimento e desenvolvimento, escores de escalas antropométricas e que constam na caderneta de saúde da criança;

b) planejamento das ações - de acordo com a idade cronológica e a idade corrigida, com os marcos de crescimento e desenvolvimento para a idade e os scores das escalas antropométricas que constam na Caderneta de Saúde da criança, eram feitos planos de atividade de estimulação que favorecesse o desenvolvimento das habilidades esperadas para a idade, tendo como material de apoio as Diretrizes para estimulação precoce: crianças de 0 a 3 anos com atraso no desenvolvimento neuropsicomotor, confeccionadas e disponibilizadas pelo Ministério da Saúde (MS).

c) efetivação das atividades planejadas - a partir da segunda visita, as atividade eram apresentadas às genitoras, bem como realizadas com as crianças; as mães eram incentivadas a realizar as atividades com as crianças em momentos oportunos de sua rotina, e uma vez por semana, a pesquisadora visita a família;

d) avaliação dos resultados obtidos - no decorrer de cada semana, conforme as atividades eram realizadas pelas famílias, a criança era avaliada em cada visita, para acompanhar a sua evolução na aquisição das atividades; de forma mais objetiva, a primeira e a última visita foram usadas como parâmetro para avaliação, e foram usados os parâmetros do Ministério da Saúde e o referencial teórico de Vygotsky para descrição dos resultados;

e) identificação de aprendizado a partir de problema - na última visita, as mães foram questionadas a respeito da importância da realização de tais atividades e se perceberam a evolução de suas crianças; além disso, como forma de educação em saúde, foi disponibilizada uma cartilha de Estimulação Precoce feita pelo Projeto de Extensão Estimulação Precoce na Primeira Infância (Edital/UFAL) (Vieira, 2019).

A pesquisa-ação considera, entre outros aspectos, a interação entre pesquisador e pessoas envolvidas na situação investigadas; a relação entre estes pares define a ordem de prioridades e as soluções encaminhadas; todos os envolvidos participam do processo de decisão, ações e atividades; e por fim, é uma pesquisa que não se limita à ação, mas pretende-se contribuir para o conhecimento das pessoas e grupos considerados (Thiollent, 2018).

Foi submetida à aprovação pelo Comitê de Ética em Pesquisa da Universidade Federal de Alagoas, e obteve parecer favorável, com Certificado de Apresentação e Apreciação Ética (CAAE) de $\mathrm{n}^{\circ}$ 15172619.9.0000.5013, garantindo-se o rigor 
ético e o cumprimento da Resolução CNS n 466/2012 e Resolução n 510/2016 do Conselho Nacional de Pesquisa em Saúde que envolve seres humanos.

\section{Resultados}

Os dados foram separados inicialmente por caso, sendo em seguida compilados os principais achados, que foram o subsídio para realização do planejamento das atividades. Cada criança foi avaliada individualmente, considerando os riscos para seu desenvolvimento, faixa etária e marco de desenvolvimento para a idade. A cada visita, era registrada a evolução da criança, interação com a genitora, a forma como a mãe reagiu e realizou a atividade. Vale destacar, ainda, que o parâmetro utilizado para classificação e/ou indicação de atraso no desenvolvimento das crianças foram a Caderneta de Saúde da Criança e o Caderno de Atenção Básica n³3 - Saúde da Criança: Crescimento e Desenvolvimento.

\subsection{Apresentação das Histórias}

\subsubsection{A história de Rosa*}

Rosa* era acompanhada mensalmente, em consulta ambulatorial no hospital de referência onde nasceu. Possuía a Caderneta de Saúde da Criança, entretanto, seu preenchimento apresentava-se insatisfatório. O resumo dos primeiros dados coletados consta no Quadro 1.

Quadro 1 - Principais achados sobre Rosa*.

\begin{tabular}{|c|c|}
\hline Dados de identificação & $\begin{array}{l}\text { - Raça preta } \\
\text { - 7m19d de idade cronológica/3m3d de idade corrigida }{ }^{1} \\
\text { - Gestação na adolescência } \\
\text { - Baixa renda }\end{array}$ \\
\hline História familiar & $\begin{array}{l}\text { - Genitora sem comorbidades } \\
\text { - Histórico familiar de diabetes e hipertensão arterial (avó paterna) }\end{array}$ \\
\hline Dados perinatais & $\begin{array}{l}\text { - História de queda de cavalo } \\
\text { - Arbovirose no quarto mês de gestação } \\
\text { - Parto vaginal, } 33 \text { semanas } \\
\text { - Peso ao nascimento: } 1855 \mathrm{~g} \\
\text { - Gestação não planejada e de risco } \\
\text { - História de internação devido à prematuridade, sepse, pneumonia e icterícia alta }\end{array}$ \\
\hline Avaliação & $\begin{array}{l}\text { - Reflexos positivos } \\
\text { - Postura semifletida, coluna íntegra } \\
\text { - Vínculo satisfatório } \\
\text { - Após período de aleitamento materno exclusivo, encontra-se em transição alimentar } \\
\text { - Vacinação atualizada } \\
\text { - Dados antropométricos: } 7 \mathrm{~kg}, 59 \mathrm{~cm} \text { de estatura e } 40 \mathrm{~cm} \text { de perímetro cefálico } \\
\text { - Demonstrou desvio em escore z relacionado ao peso }\end{array}$ \\
\hline $\begin{array}{l}\text { Marcos de Crescimento e } \\
\text { desenvolvimento }\end{array}$ & $\begin{array}{l}\text { Marcos: apresenta como positivos os marcos de busca ativa de objetos, leva objetos à boca, localiza } \\
\text { o som e rola ativamente. }\end{array}$ \\
\hline
\end{tabular}

${ }^{1}$ Idade corrigida: subtração, da idade da criança, do número de semanas que faltou para que ela completasse 40 semanas (Ministério da Saúde, 2012). Fonte: Autores (2020).

No que se refere à alimentação, estava em período de introdução alimentar, após período em aleitamento materno. Na pesquisa dos marcos de crescimento e desenvolvimento, os atrasos não eram tão evidentes quanto no segundo caso, mas optouse em realizar as atividades devido aos fatores de risco. 
Entre os genitores, algumas características podem ser ressaltadas, por trazerem peculiaridades aos casos: ambos eram adolescentes, viviam em residência de alvenaria de quatro cômodos que pertencia a outro familiar, e possuíam uma renda mensal baixa, de pouco mais de 100 reais. A gestação não havia sido planejada, e foi considerada de risco devido à queda de cavalo no primeiro trimestre.

A proposta inicial era explicar e ensinar as intervenções para os pais, incentivando que essas não fossem executadas apenas nos momentos de visita, mas também no cotidiano da família. Embora houvesse incentivo, somente a mãe da criança acompanhou e realizou as atividades, seja pelo pai estar em horário de trabalho ou não demonstrar interesse. Ainda assim, por parte da mãe, houve desinteresse e desatenção, embora tenha sido reafirmada a necessidade da realização das atividades. Os horários para a visita foram acordados previamente para propiciar o momento em que a criança estivesse mais ativa e pudesse estar mais alerta.

As visitas para Rosa* que inicialmente seriam realizadas em quatro semanas consecutivas, mas devido a fatores relacionados à relação dos pais, não foi possível. A genitora, quando questionada sobre a realização da estimulação em sua rotina, relatou que não fez atividades com Rosa* por estar cansada ou ocupada em outras atividades, em mais de uma das visitas. Eventualmente os encontros aconteciam na casa da avó do pai da criança, por ser próxima a residência deles, e outros aspectos eram observados, como a interação da criança com outras crianças, sua interação com o espaço e com a mãe. Ainda que desde o início ela tenha se demonstrado aberta a participar da atividade, durante os encontros a genitora parecia pouco à vontade, se distraindo em outras atividades, embora não tenha deixado a criança sozinha em nenhum momento.

\subsubsection{A história de Bela*}

Bela* nasceu em um Hospital vinculado a um Plano Assistencial Privado, onde seguiu em acompanhamento mensal. , indo para a Unidade de Saúde apenas para acompanhamento de situação vacinal. Sua Caderneta de Saúde da Criança foi fornecida pelo hospital, em que seus dados estavam incompletos. Em relação aos marcos de crescimento e desenvolvimento, Bela apresentava atrasos importantes, evidenciados pelo desvio em escore $\mathrm{z}$ de dois pontos, atribuído ao seu perímetro cefálico e, pela ausência de dois marcos: busca ativa por objetos e rolar ativamente. Durante a primeira avaliação, apresentou-se menos ativa; a mãe relatou que ela interage bem com o ambiente e familiares, como evidenciado em uma das visitas, onde a criança relacionavase bem com outras crianças e adultos. Os principais dados registrados constam no Quadro 2. 
Quadro 2 - Principais achados sobre Bela*.

\begin{tabular}{|l|l|}
\hline Dados de identificação & $\begin{array}{l}\text { - Raça preta } \\
\text { - } 5 \mathrm{~m} 12 \mathrm{~d} \text { idade cronológica, 4m7d idade corrigida }\end{array}$ \\
\hline História familiar & - Genitora relata Diabetes Mellitus tipo 2, insulino dependente \\
\hline Dados perinatais & $\begin{array}{l}\text { - Histórico de aborto na primeira gestação } \\
\text { - Gestação planejada } \\
\text { - História de infecção urinária tratada no primeiro trimestre } \\
\text { - Parto vaginal com 34s2d de idade gestacional } \\
\text { - Internação por três dias devido a prematuridade }\end{array}$ \\
\hline Avaliação & $\begin{array}{l}\text { - Reflexos positivos } \\
\text { - Postura semi fletida, coluna íntegra } \\
\text { - Vínculo satisfatório } \\
\text { - Faz uso de composto lácteo e introdução de frutas, não houve período satisfatório em } \\
\text { aleitamento materno } \\
\text { - Vacinação atualizada } \\
\text { - Dados antropométricos: PC 40,5cm } \\
\text { - Demonstrou desvio relacionado ao perímetro cefálico }\end{array}$ \\
\hline $\begin{array}{l}\text { Marcos de Crescimento e } \\
\text { desenvolvimento }\end{array}$ & $\begin{array}{l}\text { Marcos: Localiza o som e leva objetos à boca } \\
\text { *Observa-se que a criança não é tão ativa, e demonstra atraso em pelo menos dois marcos de } \\
\text { desenvolvimento. }\end{array}$ \\
\hline
\end{tabular}

IIdade corrigida: subtração, da idade da criança, do número de semanas que faltou para que ela completasse 40 semanas (Ministério da Saúde, 2012). Fonte: Autores (2020).

Os genitores de Bela* são mais velhos, e sua gestação foi planejada. Em relação aos fatores de risco para a gestação, a genitora relatou que possuía história de aborto anterior, ser diabética (tipo 2) e que houve, durante a gestação, uma infecção urinária tratada logo no primeiro trimestre, entretanto nada foi mencionado em relação a gestação ser tratada como de risco ou não. Em relação à interação da criança com os genitores e o ambiente, sua mãe relatou que ela era "molinha", tinha pouca interação e resposta aos estímulos.

Durante todo o acompanhamento, a genitora ficou bastante interessada e participativa nas atividades, questionando e estando atenta ao que ocorria com Bela*. A princípio, mostrou-se preocupada com o desenvolvimento de sua filha, o que foi sanado no decorrer das visitas e notado por ela, já que, como ela relatou, com a realização das atividades ela vinha percebendo sua filha mais "esperta". No que tange à realização de atividades em momentos da rotina, a genitora de Bela relatou a realização das atividades e outras interações com a criança, tanto da parte dela como de seu esposo, quando este estava presente em casa.

As atividades eram realizadas tanto no sofá de sua casa como no chão, este devidamente protegido com manta. A responsável foi incentivada a aproveitar e explorar outros espaços, além da cama e do sofá, como ambientes para a estimulação. Até a penúltima visita agendada realizada, os pais da criança haviam se separado, e a mãe de Bela passou a residir junto com sua mãe, irmã e sobrinho.

\subsection{Planejamento de atividades}

Com base na avaliação dos marcos de crescimento e desenvolvimento infantil, montou-se um plano de intervenções que contemplasse a faixa etária dos indivíduos (Quadro 3). Por estarem em idades aproximadas, o mesmo planejamento serviu para ambos os casos. O plano contemplava ações de estímulo para diversas dimensões (sensorial, visual, auditiva, comunicação e motricidade). Para confecção do plano, foi utilizado como material de apoio as Diretrizes para estimulação precoce: crianças de 0 a 3 anos com atraso no desenvolvimento neuropsicomotor, de 2016.

Quadro 3 - Plano de atividades de estimulação precoce. 


\begin{tabular}{|l|l|}
\hline DIMENSÃO TRABALHADA & ATIVIDADE PROPOSTA \\
\hline Estímulo motor/tátil & $\begin{array}{l}\text { - Uso de bolas de diferentes texturas: rolar bolas de diferentes texturas próximo à criança, aguçando } \\
\text { sua curiosidade, fazendo com que ela busque o objeto e estimulando o tato (as texturas utilizadas } \\
\text { foram o emborrachado, bolinhas de algodão). } \\
\text { - Realizar atividades com a criança em decúbito dorsal e sentada, promovendo a movimentação - sob } \\
\text { constante vigilância. } \\
\text { - Usar potes e pedir/ensinar a criança a colocar objetos dentro deste pote. }\end{array}$ \\
\hline Estímulo auditivo/visual & $\begin{array}{l}\text { - Uso de chocalhos e penduricalhos: movê-los em frente da criança, incentivando que a mesma } \\
\text { busque com a mão os objetos. }\end{array}$ \\
\hline Estímulo cognitivo/linguagem & $\begin{array}{l}\text { - Promover o estímulo à linguagem a partir da comunicação com a bebê, repetindo palavras, usando } \\
\text { o som de animais. }\end{array}$ \\
\hline
\end{tabular}

Fonte: Autores (2020).

\subsection{Execução das atividades e resultados encontrados}

Durante a primeira visita, as atividades de estimulação precoce foram apresentadas e demonstradas, com o objetivo de incentivar as genitoras a realizar as atividades apresentadas em momentos diferentes daqueles das visitas. Os materiais e brinquedos utilizados eram adequados para a faixa etária, de custo acessível e foram selecionados de forma que despertassem a atenção das crianças, por serem coloridos. Para estimulação sensorial foram usados algodão, emborrachado e outros materiais que faziam parte dos brinquedos das crianças, como chocalhos e peças de encaixe. As principais diferenças em relação à primeira e a última visita foram descritas no quadro 4.

Como já foi mencionado, houve um grau de comprometimento diferente entre as duas famílias, o que influenciou na aquisição de habilidade da criança, evidenciando que os fatores de risco têm importância nessas habilidades. Bela* teve uma ótima evolução em relação a sua postura, conseguindo sustentar a cabeça e algum controle cervical, que ainda eram instáveis no primeiro dia, mas ambas avançaram positivamente, no que se refere à dimensão motora, e também não houve nenhum tipo de rejeição com as texturas diferentes utilizadas.

Enquanto isso, Rosa* gradualmente sentava sem apoio e era estimulada a engatinhar e andar com apoio. A outra criança demonstrou desenvolvimento de movimento de pinça, e estava mais atenta aos objetos usados a cada atividade, demonstrando também mais força em membros superiores.

Já em relação às dimensões auditiva, visual e de linguagem, Rosa* demonstrou evolução na apreensão da atenção relacionada ao estímulo auditivo e visual, com sustentação de interesse por mais tempo, como também maior interação social e busca de som, ao se virar na direção em que era chamada. Bela* progressivamente mudou sua forma de interação, que passou de muito pouca interação na primeira visita, para interação por meio de balbucios e gritos, correspondendo melhor as tentativas e chegando a respondê-las. Ao usar objetos para estímulo de campo visual, a criança girava a cabeça conforme mudava-se a posição do objeto, demonstrando interesse em captá-lo.

Foram realizadas, em conjunto com as genitoras, cerca de quatro visitas, com tempo médio de 45 minutos cada sessão de intervenção. Tinham caráter instrucional e, junto com a cartilha de Estimulação Precoce disponibilizada, foi incentivada a realização das atividades pelos pais da criança, mas não houveram mais visitas. Poucos dias após a última visita, o Decreto Estadual nº6.529/2020 instalou o estado de emergência em decorrência da pandemia de COVID-19.

Quadro 4 - Comparativo entre a primeira e a última semana de Estimulação, em relação às atividades propostas. 


\begin{tabular}{|c|c|c|}
\hline Atividades realizadas & Rosa & Bela \\
\hline $\begin{array}{l}\text { Uso de bolas de diferentes texturas: rolar } \\
\text { bolas de diferentes texturas próximo à } \\
\text { criança, aguçando sua curiosidade, } \\
\text { fazendo com que ela busque o objeto e } \\
\text { estimulando o tato. }\end{array}$ & $\begin{array}{l}\text { Primeira semana: A criança interagia bem } \\
\text { com as diferentes texturas; } \\
\text { Última semana: Segue não demonstrando } \\
\text { incômodo a diferentes texturas, manuseia } \\
\text { tanto com as mãos como leva os objetos à } \\
\text { boca. }\end{array}$ & $\begin{array}{l}\text { Primeira semana: Realizado a partir da } \\
\text { segunda semana, e a criança não estranha } \\
\text { texturas diferentes; } \\
\text { Última semana: criança adaptada às texturas, } \\
\text { não estranha. }\end{array}$ \\
\hline $\begin{array}{l}\text { Realizar atividades com a criança em } \\
\text { decúbito dorsal e sentada, promovendo a } \\
\text { movimentação - sob constante vigilância. }\end{array}$ & $\begin{array}{l}\text { Primeira semana: a criança senta sem } \\
\text { apoio por alguns segundos, mas não se } \\
\text { sustenta por muito tempo; } \\
\text { Última semana: já se sustenta sozinha } \\
\text { sentada, iniciou o processo de engatinhar } \\
\text { e, com apoio, já se levanta e ensaia alguns } \\
\text { passos. }\end{array}$ & $\begin{array}{l}\text { Primeira semana: a criança realizou algumas } \\
\text { atividades sentada e com apoio, além de } \\
\text { deitada, ela não possui ainda o controle da } \\
\text { cervical; } \\
\text { Última semana: com a realização das } \\
\text { atividades, aos poucos a criança tem } \\
\text { demonstrado maior controle e sustentação da } \\
\text { cervical, e com relação às atividades em que } \\
\text { está sentada, está ainda tem sido feita com } \\
\text { ajuda de apoio leve; a criança demonstra } \\
\text { preferir atividades em pé ou deitada. }\end{array}$ \\
\hline $\begin{array}{l}\text { Usar potes e pedir/ensinar a criança a } \\
\text { colocar objetos dentro deste pote. }\end{array}$ & $\begin{array}{l}\text { Primeira semana: realizada a partir da } \\
\text { segunda visita, a criança não solta o objeto } \\
\text { logo com o primeiro pedido, sendo } \\
\text { necessário reforçá-lo; } \\
\text { Última semana: a criança larga os objetos, } \\
\text { tanto no pote como sem aparatos, busca o } \\
\text { som e pede que alguém os pegue do chão. }\end{array}$ & $\begin{array}{l}\text { Primeira semana: o pegar e soltar está sendo } \\
\text { desenvolvido; } \\
\text { Última semana: a criança tem mostrado melhor } \\
\text { controle e desenvolvimento do movimento de } \\
\text { pinça. }\end{array}$ \\
\hline $\begin{array}{l}\text { Uso de chocalhos e penduricalhos: movê- } \\
\text { los em frente da criança, incentivando que } \\
\text { a mesma busque com a mão os objetos. }\end{array}$ & $\begin{array}{l}\text { Primeira semana: busca ativamente os } \\
\text { objetos, acompanha com os olhos e leva-os } \\
\text { à boca; } \\
\text { Última semana: Os sons despertam e } \\
\text { prendem sua atenção por mais tempo, } \\
\text { ainda que eventualmente ela se distraia. }\end{array}$ & $\begin{array}{l}\text { Primeira semana: ela não busca, e parece se } \\
\text { frustrar por não saber como pegar o objeto a } \\
\text { uma distância um pouco mais; quando o objeto } \\
\text { é aproximado, ela tem mais facilidade para } \\
\text { pegá-lo; } \\
\text { Última semana: busca ativa pelos objetos, } \\
\text { demonstra maior força nas mãos, } \\
\text { acompanhando os objetos com os olhos e } \\
\text { corpo; está mais atenta e interage por mais } \\
\text { tempo com o objeto e/ou a pessoa com quem } \\
\text { está realizando a atividade. }\end{array}$ \\
\hline $\begin{array}{l}\text { Promover o estímulo à linguagem a partir } \\
\text { da comunicação com a bebê, repetindo } \\
\text { palavras, usando o som de animais. }\end{array}$ & $\begin{array}{l}\text { Primeira semana: Tentou-se chamar a } \\
\text { atenção da criança algumas vezes, mas na } \\
\text { primeira visita houve apenas o relato da } \\
\text { mãe, sem muitas interações; } \\
\text { Última semana: começou a interagir e } \\
\text { emitir alguns sons, e quando chamada pelo } \\
\text { nome, volta sua atenção para a pessoa e/ou } \\
\text { direção de onde vem o som. }\end{array}$ & $\begin{array}{l}\text { Primeira semana: a genitora relata que a } \\
\text { criança faz poucos sons, sendo o choro sua } \\
\text { expressão mais presente; a mesma relata ainda } \\
\text { que sempre que pode, conversa e interage com } \\
\text { o bebê; } \\
\text { Última semana: a criança está mais ativa no } \\
\text { período da manhã, mas interage e reage bem } \\
\text { aos estímulos quando é chamada. }\end{array}$ \\
\hline
\end{tabular}

Fonte: Autores (2020).

No que se refere a metodologia de abordagem e realização das atividades, a visita domiciliar foi um pressuposto facilitador, visto que oportunizou que o seguimento das intervenções ocorresse de forma satisfatória, sendo a visita remarcada quando houve, em um ou outro caso, um empecilho. Destaca-se, nesse ponto, a participação dos ACS que tornaram a busca possível e que foram, ao longo do processo, imprescindíveis para comunicação com a comunidade e o término das atividades.

Quando se comparou a evolução nos dois casos, observou-se que a primeira criança possuiu uma evolução mais lenta, o que pode ser resultado, entre outros fatores, de ter pais adolescentes e não haver a manutenção das atividades de estimulação na rotina, conforme relatado pela genitora. Já no segundo caso, houve maior interesse e preocupação com a manutenção dessas atividades, o que corroborou para o ganho de habilidades observado ao final do estudo. 


\section{Discussão}

Com base no que foi encontrado a partir do estudo, puderam ser enumeradas três temáticas a serem aprofundadas: fatores de risco para o desenvolvimento, acompanhamento e avaliação do crescimento e desenvolvimento e resultados da estimulação precoce para o desenvolvimento infantil das crianças prematuras.

\subsection{Fatores de risco para o desenvolvimento}

De acordo com Neves et al., (2016), em estudo realizado com crianças economicamente desfavorecidas, foram encontrados déficits de estatura para a idade e resultados abaixo da média para o desenvolvimento cognitivo e a linguagem expressiva entre crianças entre 24 e 36 meses de idade. Baixa renda familiar e evasão escolar que culminou em baixa escolaridade foram fatores importantes que tiveram influência na execução de atividades de estimulação para uma das crianças. Silva, Veríssimo e Mazza (2015) afirmaram que, crianças em condições de baixa escolaridade, pobreza, condições precárias de moradia, desnutrição e falta de acesso a recursos educacionais e de saúde demonstraram atraso no seu desenvolvimento.

A pobreza é um agente promotor de exposição a outras adversidades, como o estresse familiar, negligência, insegurança alimentar e outros (Camilo, 2018). Somados à prematuridade, indicam importante risco ao seu desenvolvimento. Da mesma forma, em um dos casos, ambos os pais possuíam ensino médio completo, enquanto para a segunda criança, os pais ainda não haviam terminado e nem estavam, no momento, frequentando as aulas. Para o mencionado autor, a baixa escolaridade materna é um fator de risco ao desenvolvimento infantil, principalmente quando associada à pobreza. Para Vygotsky, o ambiente externo tem uma importante relevância para o desenvolvimento infantil, sendo o desenvolvimento completo humano um processo 28 que surge de dentro para fora e que é influenciado pelas interações que a criança constrói (Oliveira Machado; Cavalcante, 2018).

Segundo Andrade et al., (2020), em pesquisa que visava compreender aspectos relacionados à maternidade para a mencionada faixa etária, um dos pontos levantados foi que adolescentes com menores recursos socioeconômicos e individuais tendem a ser menos preparadas para cuidar de seus filhos, podendo essa vulnerabilidade ser ampliada quando não há uma rede de atenção para suporte. Ao longo das visitas, o que se pode perceber foi que muitas vezes, no caso da mãe adolescente, que ela não estava tão interessada nas atividades realizadas para a criança, e eventualmente, se distraía realizando estas atividades ou fazendo uso de celular enquanto era realizada a estimulação, enquanto o pai, já maior de idade (18 anos), ainda que estivesse em casa no momento das atividades, não tinha qualquer interesse em participar.

Durante a adolescência, a gestação/maternidade e paternidade são consideradas uma questão social importante, visto que as variáveis de desenvolvimento físico, psicológico e social do adolescente podem significar risco à criança, caracterizado pela responsabilidade precoce imposta em decorrência da gravidez não planejada, evasão escolar e impressões negativas no que diz respeito a paternidade na adolescência (Soares; Rocha; Araújo Filho, 2016).

Vygotsky afirma que o desenvolvimento humano decorre de um processo de construção ao longo da história de cada ser, e para isso, cada um faz uso de características socioculturais e de símbolos e instrumentos que lhe são oferecidos (De La Taille; De Oliveira; Dantas, 2019). Afirma, ainda, que a relação que a criança constrói com a mãe é recheada de signos e significados, sendo a mãe uma figura de referência na qual a criança se apoia; neste sentido, ela é a figura central para o cuidado da criança. Para Vygotsky, o desenvolvimento cognitivo infantil pode ser mediado através de símbolos, como é o caso dos brinquedos e das brincadeiras, e através do brinquedo, com o uso de situações imaginárias, o processo de desenvolvimento cognitivo ocorrerá (Dos Santos Teixeira, 2017).

Em pesquisa realizada por Saccani, Martins \& de Oliveira (2017), evidenciou-se que em crianças com idade de nascimento pareada em 36 semanas, o grupo de crianças com baixo peso apresentou pior desempenho motor no primeiro ano de vida, quando comparados com grupo de crianças que apresentou peso adequado ao nascimento. A idade de nascimento dos 
sujeitos da pesquisa foram 33 semanas e 34 semanas e 2 dias. Desta forma, destaca-se a importância do uso de metodologias que colaboram positivamente com seu desenvolvimento, buscando a melhora na aquisição de habilidades. Apesar da idade aproximada, as crianças do estudo possuíam diferentes níveis de atraso, o que pode ser evidenciado na fala de Ribeiro et al., (2017), quando foi observado que crianças prematuras podem ter variáveis níveis de prejuízo ao crescimento, no que se refere aos domínios motor grosso, fino, pessoal-social e linguagem.

Apesar de apenas uma das crianças ter sido amamentada, ambas possuíam bom vínculo com a mãe, entretanto, existe risco para vínculo não satisfatório. Segundo Monteiro et al., (2020), a interação da mãe e do bebê pode trazer impactos em relação ao seu desenvolvimento, estando o esse diretamente relacionado a uma boa interação materna, além dos aspectos socioeconômicos e culturais que podem vir a contribuir com essas variáveis. Em pesquisa realizada por Oliveira Severiano et al., (2017), inferiu-se que crianças que tiveram menos de seis meses em aleitamento materno tiveram maior prevalência em atraso de desenvolvimento do que outras em que o aleitamento foi mantido por mais tempo.

Para Lev Vygotsky, a zona de desenvolvimento proximal (ZDP) é a responsável pela capacidade da criança aprender através das interações que faz com os outros, e a partir disso, com o tempo, ela consegue se desenvolver sozinha, ou seja, a interação foi um processo mediador que trouxe um benefícios para ambos componentes da interação (Rodrigues 2017).

Segundo Pontes et al., (2018), em revisão que avaliou a importância do aleitamento materno nos primeiros seis meses de vida, evidenciou-se que este tem grande influência para o desenvolvimento do sistema imune, redução nos índices de desenvolvimento de distúrbios gastrointestinais, ajuda no desenvolvimento cognitivo e crescimento favorável. Para Braga (2020), a amamentação também está relacionada ao favorecimento à fonação, respiração e deglutição. Quando se avaliou os dois casos, a mãe que possuía maior idade e renda passava maior tempo com a criança, além de demonstrar maior preocupação com seu desenvolvimento e aplicar com maior frequência as atividades de estimulação propostas.

\subsection{Acompanhamento e Avaliação do Crescimento e Desenvolvimento}

O acompanhamento de prematuros na atenção básica está atrelado à terceira etapa de método Canguru, que visa colaborar para a redução da mortalidade e dos custos com a internação hospitalar, por meio do acolhimento aos pais, promoção do contato pele a pele com o bebê, promoção do vínculo e estímulo ao desenvolvimento neurocomportamental (Gesteira et al., 2016; Brasil, 2019). Entretanto, foi possível constatar em ambos os casos o que já afirma uma série de autores, que o acompanhamento na atenção primária não ocorre de forma satisfatória, sendo necessárias estratégias como a busca ativa e a visita domiciliar para a promoção de uma assistência de maior qualidade a essas crianças.

Aires et al., (2017) reforçaram que o acompanhamento em referência e contrarreferência não são colocados em prática, e também sinalizaram aspectos que poderiam ser melhorados para a oferta dessa atenção, entre os quais se pode citar o fortalecimento da comunicação entre os profissionais (atenção primária e atenção hospitalar) e a sensibilização em relação ao registro dos atendimentos, já que a caderneta de saúde da criança pode e deve ser usada para isso. Ressalta-se, ainda, que o acompanhamento em unidades de referência ou especializadas não exclui a necessidade de vigilância através da atenção básica, com a promoção de uma rede de apoio não só de assistência à saúde, mas também de assistência social, creche e escolas (Brasil, 2016).

Além disso, a consulta a uma criança prematura deverá trazer um acompanhamento mais fidedigno em relação aos dados antropométricos e aos marcos de desenvolvimento, sendo necessário fazer a correção da idade. Em relação aos dados referentes aos partos, Fernandes et al., (2017) correlacionaram o baixo peso ao nascer a alterações de postura, linguagem e sociabilidade, o que pôde ser percebido nas crianças acompanhadas pelo estudo, já que em um dos casos, a criança não possuía ainda coordenação para manutenção da postura, sem conseguir levantar a cabeça e manter-se apoiada nos antebraços, quando 
colocada de bruços. No que se refere à dimensão da linguagem, durante a primeira e segunda visitas, foi observado que as crianças emitem poucos sons e interagiam pouco.

O Ministério da Saúde, por meio do Caderno de atenção básica n³3, que trata do Crescimento e Desenvolvimento (2012), propõe um algoritmo para vigilância de desenvolvimento infantil. Com base nos achados do exame e avaliação de marcos do desenvolvimento neuropsicomotor, pode-se dizer que as crianças se encontram, respectivamente, em alerta para o desenvolvimento no primeiro caso e com provável atraso no segundo caso, visto a associação entre fatores de risco, classificação de escore de perímetro cefálico e ausência de marcos.

\subsection{Estimulação Precoce em Crianças Prematuras durante a Visita Domiciliar}

Em pesquisa realizada por Horta e Soares (2020), evidencia-se a necessidade de acompanhamento multiprofissional para o desenvolvimento de crianças prematuras, visto que quanto mais cedo for realizada a detecção de fatores de risco e prejuízos ao desenvolvimento, melhor será o prognóstico com a intervenção e acompanhamento longitudinal e individualizado, minimizando os atrasos de desenvolvimento. As experiências sensório-motoras oferecidas à criança são responsáveis pelo rearranjo de sinapses e redes neurais para o estabelecimento de habilidades motoras; a evolução na aquisição dessas habilidades é gradual e organizada (Brasil, 2016, pg. 48).

Segundo Rosa et al., (2019), a estimulação precoce motora quando comparada a tratamentos convencionais, se mostrou eficaz, tendo efeito positivo sobre o desenvolvimento das crianças. Trabalhar a motricidade possibilitará maior quantidade de estímulos que, junto a neuroplasticidade, construirão experiências que atuarão na melhora da qualidade das atividades diárias. Ao promover atividades de estimulação motora, deve-se trabalhar e reforçar movimentos que favoreçam o tônus e a força muscular; o uso de diferentes texturas contribui consideravelmente para o desenvolvimento infantil (Brasil, 2016).

A realização de atividades que promovem o controle cervical visa favorecer a capacidade da criança, tornando-a apta para manutenção do equilíbrio (Campos, 2017). Cada interação da criança com o ambiente pode representar um potencial estimulador, desde a interação com pais e familiares, até atividades como o banho, alimentação e troca de posição (Brasil, 2016).

Em estudo realizado por Carniel et al., (2017), indicou-se que fatores como a idade gestacional, peso ao nascer e índice de apgar influenciaram negativamente na aquisição da linguagem, sendo este atraso observado já em habilidades pré-verbais e durando até a adolescência, comprometendo a aprendizagem. Os mesmos autores afirmaram, ainda, a importância da relação e interação entre mãe e bebê para a aquisição da linguagem, demonstrando que no caso de mães mais preocupadas em educar do que estimular suas crianças, seus filhos apresentaram maior déficit nos testes que envolviam a linguagem.

A audição é formada durante a gestação, e a partir dela ocorre a organização de processos neuropsicológicos, orgânicos, afetivos e simbólicos. Já o desenvolvimento visual depende, além da estruturação normal, de uma série de outros fatores. É através da visão que a criança integra informações recebidas por outros sentidos, além de intermediar o desenvolvimento motor, cognitivo e pessoal-social (Brasil, 2016, pg. 23 e pg. 31).

Segundo Fattore et al., (2017), a prematuridade afeta diretamente o desenvolvimento da linguagem, sendo os RN prematuros propensos a menor capacidade de desenvolvimento de balbucio que crianças a termo; os mesmos autores referem ainda que a frequência de sons produzida aos seis meses de idade está relacionada a aquisição de vocabulário e a complexidade dos sons, relacionada à aquisição rápida de palavras. Por depender da congruência entre diversos fatores, tais como a função sensorial, perceptiva, intelectual, e maturação cerebral, a ausência ou escassez de estimulação pode ter grande influência na aquisição dessas habilidades; a interação com outro ser humano é fundamental em todo processo de desenvolvimento (Brasil, 2016, pg. 68).

Nas duas crianças acompanhadas pelo estudo, o que se pode verificar foi a menor frequência de interações sonoras, ao menos presenciadas pela pesquisadora. Entre a primeira e a última visita de intervenções, constatou-se maiores interações, 
principalmente no segundo caso, onde a criança estava bem mais ativa e responsiva aos estímulos. A estimulação da linguagem pode ser feita de forma interdisciplinar, com auxílio também dos pais, atribuindo ludicidade e atração para a criança; a interação da criança com a família, bem como momento de contação de histórias e diálogos entre genitores e crianças podem favorecer a aquisição de linguagem (Brasil, 2016).

Ressalta-se a importância da participação dos pais na realização da estimulação precoce, o que contribuiu de forma positiva no segundo caso, levando a uma maior frequência na realização das atividades e, consequentemente, resultados exitosos para a aquisição de habilidades, como ressaltou Ribeiro (2018).

Reitera-se, nesse sentido, a importância das interações sociais e da construção cumulativa do conhecimento para o crescimento e desenvolvimento infantil, como pontuou Vygotsky em sua teoria da zona de desenvolvimento proximal (Paganotti, 2011). A participação dos familiares na estimulação corresponde a ganhos neurológicos e comportamentais, enriquecendo o processo e a interação dos familiares e da criança e potencializando os efeitos da estimulação (Brasil, 2016).

\section{Considerações Finais}

Foi evidenciado que a prematuridade trouxe prejuízos para o crescimento e desenvolvimento das crianças avaliadas, e que fatores como condições socioeconômicas, idade materna e paterna, ausência ou não de fatores de risco e a realização ou não de atividades de estimulação pôde influenciar de forma direta e indireta no ganho de habilidades nessas crianças.

A estimulação precoce foi eficaz, principalmente para aquela criança que realizava mais atividades em detrimento de comprometimento e interesse de sua mãe/genitora. A realização da avaliação do crescimento e desenvolvimento infantil e do planejamento e implementação de atividades de estimulação por parte da enfermeira foi de relevante importância, visto que na atenção primária as funções trazidas pela Política Nacional de Atenção Básica - PNAB é a atenção à saúde de indivíduos em todos os ciclos da vida, e que a PNAISC coloca a vigilância ao desenvolvimento infantil como um de seus eixos principais.

Com base nos achados encontrados no processo e na análise da pesquisa, pôde-se concluir que, inicialmente, o acompanhamento de prematuros realizado na atenção básica ainda ocorre numa demanda menor do que o número de nascimentos, ao menos na unidade que foi usada como base para a pesquisa, o que corrobora com os achados da literatura. Assim, é necessário que sejam ampliadas pesquisas em relação a este acompanhamento no município para uma melhor avaliação.

Entende-se, por fim, que o número de crianças acompanhadas foi uma limitação para o estudo, sendo necessária a ampliação da população para entender de forma mais clara como a estimulação precoce pode favorecer o crescimento e desenvolvimento infantil, e como os fatores de risco podem ser superados ou não. Também é possível sugerir a realização de pesquisa que busque entender o conhecimento dos enfermeiros em relação à estimulação precoce, bem como quais fatores eles poderiam sugerir como impeditivos para a realização dessa estimulação.

\section{Agradecimentos}

Os autores declaram seu agradecimento à Universidade Federal de Alagoas (UFAL), a Escola de Enfermagem (EENF), ao Projeto de Estimulação Precoce na Primeira Infância (PEPPI/UFAL), pelo ambiente que oportunizou o interesse para pesquisa relacionada a temática, e à Secretaria Municipal de Saúde de Maceió, que oportunizou a realização da pesquisa.

\section{Referências}

Aires, L. C. D. P., Santos, E. K. A. D., Bruggemann, O. M., Backes, M. T. S., \& Costa, R. (2017). Referência e contrarreferência do bebê egresso da unidade neonatal no sistema de saúde: percepção de profissionais de saúde da Atenção Primária. Escola Anna Nery, 21(2). https://doi.org/10.5935/1414-8145.20170028

Alagoas (2020). Decreto $n^{\circ} 69.529$, de 18 de março de 2020. Institui medidas temporárias de enfrentamento da emergência de saúde pública de importância internacional decorrente do covid-19 (coronavírus), no âmbito dos órgãos e entidades da administração direta e indireta do poder executivo estadual, e dá outras providências. Governo do Estado. https://www.imprensaoficial.al.gov.br/storage/files/diary/2020/03/DOEAL-2020-03-19-COMPLETO-40jawbo0vU3JyW5iMtOkefb4QOhiXIOh0DClbNC8XOM4F9yiqQcu.pdf 
Almeida, F. G. B. D. A. (2016). Crescimento físico e desenvolvimento motor em bebês prematuros menores que 1500 gramas acompanhados até os 2 anos. http://tede.upf.br/jspui/handle/tede/1336

Andrade, R. D., Hilário, J. S. M., Santos, J. S., Silva, J. D. P., Fonseca, L. M. M., \& Mello, D. F. D. (2020). Cuidado de enfermagem materno-infantil para mães adolescentes: educação em saúde. Revista Brasileira de Enfermagem, 73 (4). https://doi.org/10.1590/0034-7167-2018-0769

Anunciação, L. L., de Lima Souza, S., de Carvalho, R. C., Aguiar, M. G. G., \& Alves, A. B. L. (2018). A pesquisa-ação como caminho promissor para intervir frente à violência escolar. CIAIQ2018, 2. https://www.proceedings.ciaiq.org/index.php/ciaiq2018/article/view/1776

Balam, G. N. (2018). Desenvolvimento sociocognitivo e psicomotor em bebês prematuros: avaliações comportamentais e de rastreamento visual aos 12 meses de idade. http://tede.mackenzie.br/jspui/handle/tede/3527

Braga, M. S. (2020). Os benefícios do aleitamento materno para o desenvolvimento infantil. Brazilian Journal of Development, 6(9), 70250-70261. https://doi.org/10.34117/bjdv6n9-468

Brasil (2015). Portaria ${ }^{\circ} 1.130$, de 5 de agosto de 2015. Institui a Política de Atenção Integral à Saúde da Criança (PNAISC) no âmbito do Sistema Único de Saúde. Brasília, DF: Presidência da República. http://bvsms.saude.gov.br/bvs/saudelegis/gm/2015/prt1130_05_08_2015.html.

Camilo, L. D. S. (2018). Avaliação do desenvolvimento infantil de crianças moradoras de comunidades em vulnerabilidade social de Maceió-AL. http://www.repositorio.ufal.br/handle/riufal/3418

Campos, D. (2011). Intervenção precoce em lactentes prematuros. Fisioterapia Brasil, 12(5), 374-378. https://doi.org/10.33233/fb.v12i5.942

Carniel, C. Z., Furtado, M. C. D. C., Vicente, J. B., Abreu, R. Z. D., Tarozzo, R. M., Cardia, S. E. T. R., \& Cerveira, R. C. G. F. (2017). Influência de fatores de risco sobre o desenvolvimento da linguagem e contribuições da estimulação precoce: revisão integrativa da literatura. Revista Cefac, 19(1), 109-118. https://doi.org/10.1590/1982-0216201719115616

De La Taille, Y., De Oliveira, M. K., \& Dantas, H. (2019). PIAGET, VIGOTSKI, WALLON: Teorias psicogenéticas em discussão. Summus editorial.

Dos Santos Teixeira, C. C. (2017). A importância da brincadeira no desenvolvimento cognitivo infantil. ID on line Revista de psicologia, 10(33), 94-102.

Fernandes, P. T. S., Santana, T. C., Nogueira, A. L., Santos, F. C., \& Bertoncello, D. (2017). Desenvolvimento neuropsicomotor de recém-nascidos prematuros: uma revisão sistemática. ConScientiae Saúde, 16(4), 463-470. https://doi.org/10.5585/conssaude.v16n4.7835

Fattore, I. D. M., Uhde, R. M., Oliveira, L. D., Roth, A. M., \& Souza, A. P. R. D. (2017). Análise comparativa das vocalizações iniciais de bebês prematuros e a termo, com e sem risco ao desenvolvimento. In CoDAS (Vol. 29, No. 4). Sociedade Brasileira de Fonoaudiologia. https://doi.org/10.1590/2317$1782 / 20172016075$

Gaiva, M. A. M., Monteschio, C. C., Moreira, M. S., \& Salge, A. M. (2018). Avaliação do crescimento e desenvolvimento infantil na consulta de enfermagem. Avances en Enfermería, 36(1), 9-21. doi: 10.15446/av.enferm.v36n1.62150

Gesteira, E. C. R., Braga, P. P., Nagata, M., Santos, L. F. C. D., Hobl, C., \& Ribeiro, B. G. (2016). Método canguru: benefícios e desafios experienciados por profissionais de saúde. Rev. enferm. UFSM, 518-528. https://doi.org/10.5902/2179769220524

Granemann, J. L., \& Anache, A. A. (2017). Processos de aprendizagem e desenvolvimento de crianças prematuras: uma temática essencial e salutar às áreas de educação e saúde. Interfaces da Educação, 8(22), 388-415. https://doi.org/10.26514/inter.v8i22.1646

Horta, K. C., \& Soares, Â. M. (2020). O desenvolvimento de crianças nascidas pré-termo ou prematuras. Brazilian Journal of Development, 6(8), 58467-58475. https://doi.org/10.34117/bjdv6n8-308

Matos, L. A., Cavalcante, L. I. C., \& Costa, E. F. Características do ambiente sociofamiliar e desenvolvimento neuropsicomotor de crianças: associações e implicações. Rev Subjetividades. 2017; 16 (3): 97-108. http://dx.doi.org/10.5020/23590777.16.3.97-108

Mello, D. F., Wernet, M., Veríssimo, M. D. L. Ó. R., \& Tonete, V. L. P. (2017). Cuidar em enfermagem na primeira infância: contribuições do reconhecimento intersubjetivo. Revista Brasileira de Enfermagem, 70(2), 465-469. https://doi.org/10.1590/0034-7167-2016-0319

Ministério da Saúde. (2012). Saúde da criança: crescimento e desenvolvimento. Cadernos de Atenção Básica, 33. http://189.28.128.100/dab/docs/publicacoes/cadernos_ab/caderno_33.pdf

Ministério da Saúde (BR). (2016). Diretrizes de estimulação precoce: crianças de zero a 3 anos com atraso no desenvolvimento neuropsicomotor decorrente de microcefalia. http://bvsms.saude.gov.br/bvs/publicacoes/diretrizes_estimulacao_criancas_0a3anos_neuropsicomotor.pdf

Ministério da Saúde (BR). (2019). Método canguru: diretrizes do cuidado. http://bvsms.saude.gov.br/bvs/publicacoes/metodo_canguru_diretrizes_cuidado_revi sada.pdf.

Monteiro, S. P. (2018). O serviço de estimulação precoce no Brasil após a política de inclusão. Pesquisa e Prática em Educação Inclusiva, 1(1), 90-100. https://periodicos.ufam.edu.br/educacaoinclusiva/article/view/4142

Monteiro, P. V. O., Cardoso, A. B. R., da Costa, L. L., Caldas, I. F. R., da Costa Cunha, K., \& Chermont, A. G. (2020). Associações entre desenvolvimento motor e sociocomunicativo de prematuros e interação mãe-bebê. Revista Brasileira de Educação e Saúde, 10(3), 177-183. https://doi.org/10.18378/rebes.v10i3.7976

Moreira $^{1}$, K. C., \& Sodré, C. L. (2018) A importância dos programas de estimulação precoce para o desenvolvimento infantil. Pontos de Vista em Diversidade e Inclusão volume 4, 86 
Neves, K. D. R., Morais, R. L. D. S., Teixeira, R. A., \& Pinto, P. A. F. (2016). Crescimento e desenvolvimento e seus determinantes ambientais e biológicos. Jornal de Pediatria, 92(3), 241-250. https://doi.org/10.1016/j.jped.2015.08.007

Oliveira Machado, J. V., \& Cavalcante, J. R. V. (2018). Reflexões sobre o desenvolvimento infantil e as aulas de educação física na perspectiva de Vygotsky. JOrnada brasileira de educação e linguagem/encontro do profeduc e profletras/Jornada de educação de Mato Grosso do Sul, 1(1). https://anaisonline.uems.br/index.php/jornadaeducacao/article/viewFile/4975/5001

Oliveira Severiano, A. A., de Sousa Dantas, D., de Oliveira, V. L. C., Mikael Lopes, J., de Souza, D. E., \& Gomes Magalhães, A. (2017). Associação entre amamentação, fatores obstétricos e o desenvolvimento infantil de crianças do interior do nordeste brasileiro. Revista Brasileira de Crescimento e Desenvolvimento Humano, 27(2). http://dx.doi.org/10.7322/jhgd.114483

Pontes, E. D. S., de Araújo, M. G. G., da Silva, C. P., de Sousa, J. T. A., Dantas, E. N. D. A., da Silva, E. B., ... \& Viera, V. B. (2018). A Importância do Aleitamento Materno nos Primeiros Seis Meses de Vida. International Journal of Nutrology, 11(S 01), Trab22. DOI: 10.1055/s-0038-1674319

Ribeiro, G. L. (2018). Intervenções precoces no desenvolvimento motor do prematuro-revisão sistemática. http://repositorio.ufu.br/handle/123456789/24333

Ribeiro, C. D. C., Pachelli, M. R. D. O., Amaral, N. C. D. O., \& Lamônica, D. A. C. (2017). Habilidades do desenvolvimento de crianças prematuras de baixo peso e muito baixo peso. In CoDAS (Vol. 29, No. 1). Sociedade Brasileira de Fonoaudiologia. https://doi.org/10.1590/2317-1782/20162016058

Rodrigues, M. M. (2017). As contribuições de Vygotsky para o desenvolvimento das crianças com deficiência. Id on Line Revista de Psicologia, 10(33), 320328.

Rosa, M. I. Z. D., Oliveira, R. P. D., Gerzson, L. R., Sbruzzi, G., \& Almeida, C. S. D. (2019). Intervenção motora precoce em bebês prematuros: uma revisão sistemática. Acta fisiátrica, 164-170. https://doi.org/10.11606/issn.2317-0190.v26i3a168767

Saccani, R., Martins, A. G., \& de Oliveira, P. (2017). Desenvolvimento motor no primeiro ano de vida de crianças prematuras conforme o peso de nascimento. Scientia Medica, 27(3), 1. https://dialnet.unirioja.es/servlet/articulo?codigo=6137839

Silva, D. I., de LaÓ Ramallo Veríssimo, M., \& de Azevedo Mazza, V. (2015). Vulnerabilidade no desenvolvimento infantil: influência das políticas públicas e programas de saúde. Revista Brasileira de Crescimento e Desenvolvimento Humano, 25(1). http://dx.doi.org/10.7322/jhgd.96760

Silva, R. M. M. D., Zilly, A., Nonose, E. R. D. S., Fonseca, L. M. M., \& Mello, D. F. D. (2020). Oportunidades de cuidados à criança prematura: visita domiciliar e suporte telefônico. Revista Latino-Americana de Enfermagem, 28. https://doi.org/10.1590/1518-8345.3520.3308

Soares, A. D. D. A. S., Rocha, S. S., Araújo Filho, A. C. A. (2016). O cuidado com o crescimento e desenvolvimento infantil: o discurso de pais e mães adolescentes. Enfermagem em foco, 7(3/4), 17-21. http://revista.cofen.gov.br/index.php/enfermagem/article/view/943/353

Teixeira, A. N., Lôbo, K. R. G., \& Duarte, A. T. C. (2016). A Criança e o ambiente social: aspectos intervenientes no processo de desenvolvimento na primeira infância. ID on line REVISTA DE PSICOLOGIA, 1O(31), 114-134. https://doi.org/10.14295/idonline.v10i31.530

Thiollent, M. (1988). Metodologia da pesquisa-ação. In Metodologia da pesquisa-ação (pp. 108-108).

Vieira, A.C.S. Cartilha de estimulação precoce na primeira infância. Editora Inovar, 2019

Yakuwa, M. S., Neill, S., \& Mello, D. F. D. (2018). Estratégias de enfermeiros para a vigilância à saúde da criança. Revista Latino-Americana de Enfermagem, 26. https://doi.org/10.1590/1518-8345.2434.3007 